\title{
Beneficence, Non-Identity, and Responsibility: How Identity-Affecting Interventions in Nature can Generate Secondary Moral Duties
}

\author{
Gary David O'Brien ${ }^{1}$
}

Received: 9 August 2021 / Revised: 9 August 2021 / Accepted: 19 August 2021 /

Published online: 27 September 2021

(c) The Author(s) 2021

\begin{abstract}
In chapter 3 of Wild Animal Ethics Johannsen argues for a collective obligation based on beneficence to intervene in nature in order to reduce the suffering of wild animals. In the same chapter he claims that the non-identity problem is merely a "theoretical puzzle" (p.32) which doesn't affect our reasons for intervention. In this paper I argue that the non-identity problem affects both the strength and the nature of our reasons to intervene. By intervening in nature on a large scale we change which animals come into existence. In doing so, we enable harmful animals to inflict harms on other animals, and we put other animals in harm's way. The harms that these animals will inflict and endure are foreseeable. Furthermore, since nonhuman animals aren't moral agents, harmful animals cannot be morally responsible for their harmful actions. I argue therefore that by causing animals to exist, knowing that they will inflict and suffer harms, we become morally responsible for those harms. By engaging in identity-affecting actions then we take on secondary moral duties towards the animals we have thereby caused to exist, and these secondary moral duties may be extremely demanding, even more so than the initial costs of intervention. Finally, these duties are duties of justice rather than duties of beneficence, and as such are more stringent than purely beneficence-based moral reasons. Furthermore, this conclusion flows naturally from several plausible principles which Johannsen explicitly endorses.
\end{abstract}

Keywords Wild Animal Suffering · Wild Animal Ethics · Kyle Johannsen · Non-Identity Problem · Environmental Ethics · Animal Ethics

Gary David O'Brien

gary.obrien@philosophy.ox.ac.uk

1 Uehiro Centre for Practical Ethics, University of Oxford, 16-17 Saint Ebbe's Street,

Oxford OX1 1PT, UK 


\section{Introduction}

Johannsen's “Wild Animal Ethics: The Moral and Political Problem of Wild Animal Suffering" (2021) has the well-deserved distinction of being the first book on an important, but thus far neglected moral issue, the problem of wild animal suffering (WAS). Johannsen offers a sophisticated account of the naturogenic causes of WAS and an analysis and critique of the idea that nature has intrinsic value (chapter 2); he engages with the literature on the ecological risks of large-scale intervention in nature and argues that the risks are manageable and acceptable, especially given the scale and severity of the problem (chapter 4), and he makes concrete proposals for radical technological interventions that promise to liberate animals from needless suffering (chapter 5). Another distinctive element of Johannsen's book is his focus on the political elements of the problem of WAS. He argues for a collective obligation to intervene in nature grounded in beneficence (chapter 3 ). Though he accepts that considerations of distributive and rectificatory justice may be important, he argues that interventionists ought to focus on beneficence-based reasons and downplay the importance of justice-based reasons for intervention on both strategic (p.44) and principled grounds (p.30, 42-43, 46).

In the same chapter in which he argues for the primacy of beneficence-based reasons for intervention Johannsen claims that the non-identity problem is merely a "theoretical puzzle" (p.32) which doesn't affect our reasons for intervention. In this paper I will argue that the non-identity problem does affect both the nature and the strength of our reasons to intervene. By intervening in nature on a large scale we change which animals come into existence. Some of these animals will be what Johannsen has called 'harmful animals', that is, animals who inflict net harm on other animals, such as predators, or r-strategists who will go on to have large numbers of uncared for offspring. Others will be 'harmed animals', animals who suffer because of the actions of harmful animals (for example, prey animals who will be killed by predators, or r-strategist animals who die shortly after birth). The harms that these animals will inflict and endure are foreseeable - we know in advance that if we cause a wolf to exist she will kill other animals, and we know that if we cause r-strategists to exist the vast majority of them will die young. Furthermore, since non-human animals aren't moral agents, harmful animals cannot be morally responsible for their harmful actions. I argue therefore that by causing animals to exist, knowing that they will inflict and suffer harms, we become morally responsible for those harms. By engaging in identity-affecting actions then we take on secondary moral duties towards the animals we have thereby caused to exist, and these secondary moral duties may be extremely demanding, even more so than the initial costs of intervention. Finally, these duties are duties of justice rather than duties of beneficence, and as such are more stringent than purely beneficence-based moral reasons. Furthermore, this conclusion flows naturally from several plausible principles which Johannsen explicitly endorses.

In section two I will flesh out the relevant moral principles I take Johannsen to be committed to. The most important of these, which I call the transformation 
principle, is the principle that we can become responsible for the harmful actions of nonhuman animals if our actions have enabled them to inflict those harms, for example, by rescuing them. In section three I will show how the responsibilitygenerating conditions which make us responsible for the harmful actions of nonhuman animals we have rescued also apply to cases in which we create harmful animals. Furthermore, by creating animals vulnerable to harm we take on some responsibility for their wellbeing. In section four I will suggest that we can similarly become responsible for natural harms when our identity-affecting interventions determine which animals come into existence. Finally, I will consider how all of this affects our moral reasons to intervene in nature.

\section{Transformation by Rescue}

When discussing the basis of our moral reasons to intervene in nature, Johannsen considers whether rectificatory justice might provide moral reasons for beneficent intervention (p.30). The idea is that, since human beings have caused, and continue to cause harm to wild animals (by climate change for example) this might generate collective moral duties to compensate animals for those harms. The rectificatory claim is that, since we are causally and morally responsible for the harms that climate change has inflicted on non-human animals, we have strong moral reasons to compensate animals for these harms. These reasons aren't based on general duties of beneficence, rather they are grounded in considerations of rectificatory justice. Furthermore, it's plausible that duties of rectification are generally stronger than duties of beneficence. That is, our duties to rectify harms for which we are responsible are stronger than our duties of beneficence to prevent equivalent harms for which we aren't responsible.

Though he accepts that considerations of rectificatory justice might play some "highly circumscribed" (p.46) role in determining which interventions ought to be funded, he rejects rectificatory justice as a general basis for intervention for two reasons. First, rectificatory justice only applies to harms caused by human beings. Since human beings aren't responsible for naturogenic harms such as those caused by r-selection and predation (which cause the vast majority of WAS), rectificatory justice cannot ground any moral reason to intervene to prevent these harms from occurring. At best, rectificatory justice can ground duties to engage in limited interventions in nature to correct the harms we have caused, while ignoring those naturogenic harms which cause most WAS. By contrast, appealing to beneficence allows us to justify a general program of intervention in nature to improve wild animal welfare, regardless of whether the causes of suffering are naturogenic or anthropogenic.

Second, rectificatory justice cannot ground duties to help harmful animals, that is, those who are likely to go on to cause significant further harms to other animals. This is because when we save the lives of harmful animals we become causally responsible for the harms they inflict. If a human being saves the life of a predator, and that predator goes on to inflict harms on other animals, the human being who knowingly allowed the predator to continue causing such harms must be responsible for them. In Johannsen's words “someone who rehabilitates a predator violates 
the rights of her prey" (p.46). Let's call this the transformation principle. The transformation principle states that human beings can transform naturogenic harms into anthropogenic ones by enabling harmful animals to harm others, for example, by saving their lives. Though humans aren't normally responsible for the harms that animals inflict on each other, by transforming these harms into anthropogenic ones we become responsible for them.

But how exactly does this transformation work? How is it that merely by saving the life of a predator a human becomes responsible for the future harms she inflicts? After all, we don't generally think that by saving the life of another human we become morally responsible for any future harms that he goes on to inflict. For example, if someone saves the life of a child drowning in a shallow pond, and then that child goes on to commit a string of murders twenty years later we don't attribute any moral responsibility to the rescuer even though the rescue was undeniably a causally necessary precondition for the subsequent murders. How are things different in the case of rescuing harmful animals?

Johannsen seems to have three responsibility-generating conditions in mind which must be met in order to transform the naturogenic harms inflicted by harmful animals into anthropogenic ones by rescuing them:

(i) Causal responsibility - by saving the life of a harmful animal we enable him to perform future harmful actions which he couldn't have performed if we hadn't rescued him. In Johannsen's words “Though human beings aren't normally the cause of harms associated with predation or the r-strategy, we become causally responsible when we save predators' or r-strategists' lives" (P.46)

(ii) Foreseeability - we can reasonably predict that the rescued animal will go on to cause harm to others. The foreseeability condition only arises in the case of rescuing harmful animals, that is, those who "will predictably go on to cause significant harms, namely r-strategist animals or predators" (p.46, italics mine)

(iii) Non moral agency - the harmful animal isn't a moral agent, and hence cannot be morally responsible for his harmful acts (p.46)

These three principles aren't intended to constitute a full account of when one can become responsible for the actions of another agent. Rather they are intended to serve as an intuitively plausible starting point for determining responsibility in such cases. Furthermore, they do seem to give the intuitively correct answer in a variety of cases. They rightly give the result that the rescuer who saves the drowning child who later becomes a serial killer isn't responsible for the killings. In that case, though the rescuer shares causal responsibility for the murders, it isn't the case that the murders were foreseeable - the rescuer had no way of knowing that the child would go on to become a killer later in life. But it should be clear that all three conditions are met when one saves the life of a harmful animal. If I save the life of a wolf, it is obviously true that I am causally responsible for the harmful actions the wolf goes on to perform, since she couldn't have performed those actions if I hadn't rescued her. It's also perfectly foreseeable that the wolf will go on to kill other animals - this is what wolves are biologically programmed to do. Finally, most people agree that non-human animals aren't morally responsible for their actions. Rescuing the wolf isn't like rescuing a human being who 
can be morally responsible for her actions, rather it is like setting in motion some purely mechanistic process that will foreseeably result in significant harms to other animals. If anyone is morally responsible for those harms, it must be the rescuer.

The transformation principle doesn't entail a general moral prohibition on rescuing harmful animals, but it does mean that we take on additional moral duties should we decide to do so. If we rescue a harmful animal then we take on secondary moral duties to either prevent, or compensate the victim for, the harms that the harmful animal will go on to inflict. If we rescue a wolf for example then we would take on the secondary moral duties to prevent her from harming other animals, perhaps by keeping her confined and feeding her synthetic proteins. These secondary duties can be understood as additional costs of rescue. In some cases, these additional costs will be high enough that we might no longer have a duty to rescue the harmful animal at all. To see this, imagine two rescue scenarios:

Rescue 1: We see an adult monkey stuck in a lake. If we do nothing she will drown. The cost to us of rescuing her is minimal - it would simply take a little bit of time and effort to drag her from the lake. Afterwards she will go on to live a life worth living without harming any other animals.

Rescue 2: We see an adult fox stuck in a lake. If we do nothing she will drown. The cost to us of rescuing her is the same as the cost of rescuing the monkey. Afterwards she will go on to live a life as worth living as the life of the monkey. However, as a predator she will inflict very serious harms on many other animals during the rest of her life. To prevent these harms, we would have to keep her in captivity and provide synthetic food for her for the rest of her life.

In rescue 1 the cost to us is very clearly outweighed by the benefits to the monkey. We have a moral duty to rescue her. Rescue 2 is very different. Though the initial cost of rescue and the benefits to the fox are the same as those in rescue 1, the fact that the fox is a harmful animal generates secondary moral duties for us after we rescue her. Since the costs of fulfilling these duties are very high, we may be justified in letting her drown. It may be a very good thing for you to rescue her and bear these secondary costs; nevertheless, unlike rescue 1, rescue 2 may be supererogatory.

Finally, these secondary moral duties to prevent or rectify the harms caused by the harmful animal one has rescued are grounded in considerations of rectificatory justice, not beneficence, and this makes a difference to their strength. By rescuing a harmful animal we become responsible for the harms that he will go on to inflict on other animals, and so we violate the negative rights of prey animals not to be harmed. The negative right not to be harmed is generally stronger than a claim to beneficence, even if the degree of harm is the same.

\section{Transformation by Creation}

Rescue isn't the only way in which we can enable a harmful animal to inflict harms, nor is it the only way in which we can become morally responsible for their harmful actions. We can also do so by creating harmful animals. We can imagine for 
example that, in order to conserve the species, conservationists decide to breed Siberian Tigers in captivity then release them into the wild. In doing so, they meet all of the responsibility-generating conditions that apply in rescue cases:

(i) Causal responsibility — by creating and releasing the tigers they enable them to inflict harms on other animals

(ii) Foreseeability - they can reasonably predict that the tigers, once released, will inflict very serious harms on other animals

(iii) Non-moral agency - the tigers aren't moral agents

It seems clear that the conservationists are responsible for the harms that the tigers will inflict on other animals. Worse still, there seems to be no reason to limit the responsibility of the conservationists to just the harms inflicted by the tigers that they are directly responsible for creating and releasing. Rather, their responsibility extends into the future, to the harms that the descendants of the released tigers will inflict on future animals. The tigers bred and released by the conservationists can reasonably be expected to breed in the wild and create new generations of tigers. And, of course, it's equally predictable that those new tigers will also go on to harm other animals, to procreate, and so on. The new generations of tigers aren't moral agents, and so they cannot be morally responsible for the harms they inflict, nor can the original generation of released tigers be held morally responsible for procreating. If the conservationists are responsible for the harmful actions of the original cohort of tigers they bred and released, it seems that they must also be responsible for the harms inflicted by future generations of tigers who would never have existed without the conservationists' intervention. If this is correct, then introducing harmful animals to environments where they can spread and multiply is an extremely weighty moral decision, one which may make one morally responsible for innumerable harms even long after one's death.

We can also become responsible for the wellbeing of harmed animals in virtue of creating them. If I deliberately choose to create an animal, knowing in advance that he will be vulnerable to harm, I have strong moral reasons to ensure that he will have a reasonable chance of having a life worth living, and this is something I owe to him as a matter of justice in virtue of having created him. ${ }^{1}$ This also applies to collective acts of creation. Think for example of the introduction of rabbits to Australia in the eighteenth century. Humans deliberately introduced breeding populations of rabbits to the country for the purpose of hunting them. It is commonly accepted that humans are morally responsible for the ecological damage that the rabbits went on to cause. It is equally true that humans must be responsible for the harms endured by the rabbits themselves - death by starvation, disease, predation, and extreme weather

\footnotetext{
${ }^{1}$ The idea that creation generates special duties for the creator to his creation seems to be widely accepted in procreative ethics, but has been little discussed when it comes to the creation of animals. See O'Brien (2021) for an argument in favour of extending this principle to the creation of animals, and Unruh (2021) who argues that causing future generations to exist grounds special duties to future generations for the present generation.
} 
conditions. Deliberate human action resulted in millions of rabbits coming to exist, rabbits which never would have existed without human intervention. This action was causally necessary for the suffering of the rabbits, it was foreseeable that the rabbits would suffer and neither the rabbits themselves nor their predators are moral agents. If humans are responsible for the wellbeing of these rabbits, then the many harmful actions we take against them for the purpose of ecological conservation are doubly wrong - not only do we inflict harms on innocent animals, but we fail to give them what we owe them as their creators.

\section{Transformation by Identity-Affecting Actions}

In this section I will suggest that some of our identity-affecting interventions are morally similar to the kinds of rescue and creation cases described above. By intervening in nature we change which animals come into existence. In the case of harmful animals we foreseeably enable them to harm others, and hence become responsible for their harmful actions. By causing them to exist we enable them to inflict harms on other animals just as much as we did in the rescue and creation cases. In the case of 'harmed-animals' it was our identity-affecting interventions which brought them into existence, and put them into harm's way. I will now explain how changing the victim of a natural harm can transform it into an anthropogenic one.

Smith and Jones 1 Smith is about to be fatally struck by lightning, a totally natural harm for which no one is responsible. You can't do anything to prevent the harm. You do, however, have the ability to change who the victim is. By clicking your fingers, you can make Smith and Jones instantly switch places. If you do so, Smith will be whisked away to safety and Jones will be put in harm's way. If you do nothing you aren't responsible for the harm that befalls Smith. If you click your fingers then you are both causally and morally responsible for the harm that befalls Jones. By deliberately substituting one victim for another you have transformed a natural harm into an anthropogenic one. You have killed Jones, and are legally and morally liable for punishment.

Smith and Jones 2 This case is the same as the first one, except that it is Smith's heart condition which makes the lightning strike fatal. Jones has no such condition - if the lightning strikes her it will be very painful, and she will spend several weeks in hospital, but she will survive. You know all of this, and are deciding what to do. If you do nothing, Smith will die. The harm is a fully naturogenic one. You aren't morally responsible for it, and you have no secondary moral duties to compensate Smith's family. If you click your fingers this will bring about a better outcome, impersonally considered (though of course it is significantly worse for Jones). You will again however have transformed a naturogenic harm into an anthropogenic one, and so you will take on secondary moral duties towards Jones. You have deliberately harmed her, and you have duties based on rectificatory justice to make things right, by paying her medical expenses for example. Clicking your fingers to bring about 
the lesser of two harms may be the right thing to do, but this fact doesn't excuse you from your secondary duties towards Jones. ${ }^{2}$

In Smith and Jones 2 the victim (Jones) already exists, and the agent takes on secondary moral duties towards the victim by diverting a natural harm from an original victim to another one of his own choosing. Can one also become morally responsible for a 'natural' harm by performing an identity-affecting action? That is, can a natural harm be transformed into an anthropogenic one not by diverting the harm from one existing individual to another, but by changing which victim comes into existence? Consider:

Mutagenic Gas - A couple is about to conceive a child. Unbeknownst to them, they are surrounded by a naturally occurring gas that will cause serious birth defects in any child who is conceived while the parents are exposed to it. You know this, but you cannot warn the couple. All you can do is launch a fireworks display, which will distract them for an hour, after which some of the gas will have dispersed, and the child they conceive will have less serious birth defects. This will however be a different child than the one they would have had if you hadn't launched the fireworks. Assume that neither child will have a life worth living, and that the parents will be unable to take care of either child.

In this case, the best outcome impersonally considered is the one in which you launch the fireworks, since in this outcome the child with less serious birth defects will be born, rather than the one with more serious defects. The outcome is bad for the child who is born however, since he doesn't have a life worth living. That child, if he were able to, would complain that your actions have harmed him. By your deliberate action, you caused this child to come into existence, knowing that he would have a bad life. Your action was causally necessary for the child's existence, and you were able to foresee that the child would have a bad life. Is it plausible that you acquire any moral duties towards the child? If you had done nothing, then the resulting child would have been nothing to do with you - you aren't causally implicated in his existence, and he would have come into existence whether you were around or not. The second child could reasonably complain to you that he has a bad life as a result of your actions. I think it is at least plausible that you have some duties towards this second child that you wouldn't have had towards the first one.

Let's now turn to large-scale identity-affecting interventions in nature. Consider:

Beneficent Intervention - There is an island populated by a species of herbivorous r-strategists, the Rs. Rs reproduce in very large numbers, and con-

\footnotetext{
2 One might argue that in this case it is actually Smith who takes on duties to compensate Jones. This is because Smith is the one who has benefitted most from the rescue. I think the objection fails in the case of nonhuman animals, though. Since animals aren't moral agents they cannot have moral responsibilities to compensate others. If we inflict some harm on an animal in order to prevent greater harms to another, it cannot therefore be the case that the benefitting animal must compensate the harmed one. The moral responsibility to compensate the harmed animal must remain with the human agent. Furthermore, in the cases under consideration the 'benefitted' animals don't exist, as we have caused different animals to come into existence in their place. Thanks to Jeff McMahan for this objection.
} 
sequently the vast majority of them die of starvation shortly after birth. Each year X number of Rs starve to death. Using gene drives we alter the DNA of the Rs so that they produce half as many offspring as they naturally would, and this means that approximately half as many $\mathrm{R}$ infants starve to death each year.

Our intervention has had two important consequences. Firstly, we have changed the identities of the Rs that come into existence. After a few generations, no particular individual in the post-intervention world would have existed had we not intervened (this includes both the harmed-animals, that is, the ones who starve to death, and the harmful-animals, those few Rs who survive long enough to reproduce). Secondly, we have made it the case that many fewer animals suffer and die each year than would have if we hadn't intervened. The result isn't better for any particular animal, but impersonally considered the situation post-intervention is far better than the situation which would have resulted if we had done nothing. Though our action has resulted in there being half as many victims of starvation each year than there would have been, it has also substituted one set of victims for a completely different set. We have made it the case that millions of Rs, who would otherwise never have existed, come into existence only to suffer and die, after living bad lives. It's true that we have reduced the harms that occur on the island. It's also true that we have done so at the cost of diverting purely naturogenic harms so that different victims are harmed instead. Essentially, we have sacrificed the wellbeing of some for the sake of the wellbeing of a greater number of others. This may well be the all-things-considered right thing to do, but this doesn't mean that we don't take on secondary moral duties towards those unfortunate creatures we have sacrificed. And those secondary duties may be very onerous indeed since they are based on the more demanding ground of justice rather than that of beneficence. Furthermore, it seems that our action meets all three of the responsibility-generating conditions outlined above:

(i) Causal responsibility - by bringing these particular animals into existence we enable the harmful ones to inflict harms, and we put the harmed-animals into harm's way

(ii) Foreseeability - we could reasonably predict that our intervention would affect the identities of the animals who come into existence, and that the majority of those animals would suffer and die prematurely

(iii) Non moral agency—none of the animals are moral agents

What kind of secondary moral duties might we acquire towards those animals we have caused to come into existence? At the very least we owe it to them to try to prevent them from starving to death, and to make their lives worth living overall. This will require further interventions on the island, and these further interventions will also affect the identities of the individuals who will come to exist, making us responsible for the harms which they inflict and endure too. All of this may be far more difficult and costly than the initial relatively simple intervention to reduce their numbers was. 
There are two objections to consider here. First we can ask whether we actually harmed any of the animals on the island by causing them to exist. If they generally live good lives overall, then it may be the case that we have actually benefitted them by causing them to exist, despite the numerous harms that they endure during the course of their lives. It may be the case that many animals do have lives worth living, assuming they survive infancy. For the r-strategists who die painfully shortly after birth (the vast majority of all animals) I think it's unlikely that their lives are worth living for them. If their lives aren't worth living, then we have harmed them by causing them to exist. Even if we assume that they do have lives worth living however, it isn't clear that we don't have any secondary moral duties towards them. Even if we have conferred on them a net benefit (a life worth living) we may still have duties to prevent them from suffering harms, or to compensate them for harms they have suffered as a result of our causing them to exist.

Secondly, we can ask whether it is in general plausible that we can acquire additional moral duties solely in virtue of having performed large-scale identity-affecting actions. After all, social policies implemented by governments also affect the identities of those who will come to exist, but we don't normally think that the resulting people are owed compensation for the harms that they endure as a result of being caused to exist. For example, if the government adopts a wide-ranging clean energy policy to prevent climate change, this will change people's behaviour, ultimately resulting in a population composed entirely of individuals who wouldn't have existed had the government adopted a different policy. ${ }^{3}$ We don't think that the government owes compensation, or any special moral duties towards the people it has caused to exist by adopting this policy. Why should the animal case be any different?

I think there are three key differences. In the case of the government's large-scale identity-affecting actions the causal responsibility for the existence of the post-intervention individuals is widely dispersed. While the government's adoption of the clean energy policy is a necessary condition for their existence, there are innumerable other actions by human agents that are also necessary, most obviously the procreative actions of the parents. This might not be the case in interventions in nature in that case there may be no downstream actions by human agents after intervention that are causally necessary for the existence of the post-intervention animals. Secondly, in the case of intervention in nature it is foreseeable that many of the animals who will exist after the intervention will have bad lives, while most human lives are worth living. Finally, many of the harms that the post-intervention people will suffer will be caused by the deliberate actions of human beings who are moral agents and thus must accept moral responsibility for those harms. In the animal case, the harms they endure aren't caused by moral agents. The moral responsibility for those harms must therefore belong to the human agents whose actions enabled them to occur.

\footnotetext{
3 This example is taken from McMahan (2020).
} 


\section{How Does this Affect our Moral Reasons to Intervene?}

I have argued that identity-affecting interventions in nature generate secondary moral duties towards the animals we cause to exist. More specifically (i) we bear some responsibility for the wellbeing of animals we create (ii) we become responsible for the harms we foreseeably enable harmful animals to inflict and (iii) we become responsible for the harms endured by harmed animals when our identity-affecting actions cause them, rather than some other animals, to suffer harms. Furthermore, the duties we acquire to these animals are duties of rectificatory justice, and hence are more stringent than comparable duties of beneficence. Far from being a mere theoretical puzzle, or undermining our reasons to intervene, the non-identity problem actually strengthens our moral duties towards wild animals, and Johannsen's emphasis on beneficence becomes more obviously a strategic move rather than a principled one.

The most obvious way this affects our moral reasons to intervene in nature is that it raises the costs of intervention. As in the rescue case above in which rescuing the drowning fox generated secondary moral duties which were more costly than the initial rescue, some of our large-scale interventions in nature seem to generate secondary duties which are extremely costly. This increase in the cost of intervention may make it permissible for us to refrain from intervening in nature at all. On the other hand, we may think that the scale and severity of the suffering endured in the natural world makes intervention mandatory, regardless of the secondary costs that may result. Once we begin systematically intervening in nature however, it may no longer be permissible for us to stop. The more we intervene in nature, the more we transform naturogenic harms into anthropogenic ones, and the more responsible we become for the overall state of the biosphere, the more duties we take on. Natural harms call for intervention, and intervention calls for more intervention, and a greater assumption of responsibility for the state of the biosphere and the wellbeing of all those individuals who compose it, individuals who, to an ever growing extent, wouldn't have existed but for our actions. Eventually, there are few truly natural harms, as the biosphere becomes more and more an artefact of human choices rather than something independent of our will. Beneficence makes us intervene in the natural world, and our interventions bring the natural world under human control, and hence into the sphere of justice.

Open Access This article is licensed under a Creative Commons Attribution 4.0 International License, which permits use, sharing, adaptation, distribution and reproduction in any medium or format, as long as you give appropriate credit to the original author(s) and the source, provide a link to the Creative Commons licence, and indicate if changes were made. The images or other third party material in this article are included in the article's Creative Commons licence, unless indicated otherwise in a credit line to the material. If material is not included in the article's Creative Commons licence and your intended use is not permitted by statutory regulation or exceeds the permitted use, you will need to obtain permission directly from the copyright holder. To view a copy of this licence, visit http://creativecommons.org/licen ses/by/4.0/.

\section{References}

Johannsen, K. (2021). Wild animal ethics: The moral and political problem of wild animal suffering. Routledge. 
McMahan, J. (2020). Climate change, war, and the non-identity problem. Journal of Moral Philosophy, 18, 211-238.

O'Brien, G. (2021). Directed panspermia, wild animal suffering, and the ethics of world-creation. Journal of Applied Philosophy. https://doi.org/10.1111/japp.12538

Unruh, C. F. (2021). The strings attached to bringing future generations into existence. Journal of Applied Philosophy. https://doi.org/10.1111/japp.12532

Publisher's Note Springer Nature remains neutral with regard to jurisdictional claims in published maps and institutional affiliations. 